\title{
Moving beyond the Build-or-Join Decision: A Multiple Case Study on Multi-Platform Strategies of Incumbent Firms
}

\author{
Sebastian Hermes \\ Technical \\ University of \\ Munich \\ sebastian.hermes \\ @ tum.de
}

\author{
Rebekka Guhl \\ Technical \\ University of \\ Munich \\ rebekka.guhl@ \\ tum.de
}

\author{
Maximilian Schreieck \\ Technical \\ University of \\ Munich \\ $\underline{\text { maximilian.schreieck }}$ \\ @ tum.de
}

\author{
Jörg Weking \\ Technical \\ University of \\ Munich \\ joerg.weking@ \\ tum.de
}

\author{
Helmut Krcmar \\ Technical \\ University of \\ Munich \\ helmut.krcmar \\ @ tum.de
}

\begin{abstract}
Companies that operate digital platforms are growing rapidly. Theoretical and empirical research has largely explored digital platforms in the context of digital-native companies. Only a small set of research explores how incumbent firms transition into the platform economy. However, this stream of research has studied incumbents under the assumption that they can either build a platform or join an existing platform. In contrast, the results of our multiple case study demonstrate that incumbents pursue multiple platform strategies simultaneously and that their strategic options range from building and joining a platform over investing in and acquiring a platform to using white-label platforms. The white-label strategy uses the platform technology of a white-label platform owner to match the users of the incumbent with the complementors of the whitelabel platform. Based on the results, which further illustrate the motivations to pursue each strategy, we discuss strategic differences between asset-heavy and asset-light incumbents.
\end{abstract}

\section{Introduction}

Six out of the ten most valuable brands in 2019 were launched by platform companies [1], several of which had existed for a surprisingly short time. By leveraging the generativity of their ecosystems [2], platform companies are disrupting traditional business landscapes by changing well-known business processes such as the creation of value, and expectations of consumers [3, 4].

To compete in the platform economy, incumbent companies must rethink their business models [5] and find new ways of creating value for their customers [6]. Otherwise, they might ultimately be displaced by new and rapidly growing platform companies [7]. However, incumbents face several challenges when entering the logic of platform ecosystems. On the one hand, they are accustomed to controlling all aspects of their business, such as the supply chain, distribution, and customer relationships $[6,7]$. On the other hand, they are less agile than their new digitalnative competitors, because their change is slowed down by organizational rigidity and structural inertia [8]. To combat the disruptive platform competition, incumbents are increasingly adopting platform thinking $[9,10]$ and establishing new platform ecosystems [5, 6]. Incumbents from highly diverse industries, such as banking, insurance, healthcare, transportation, steel distribution, and energy, are beginning to embrace platform business models [11, 12].

Although research on digital platforms made significant advances on the dynamics of platform emergence, platform orchestration, as well as platform strategies and platform competition (see [13, 14] for an extensive review), theoretical and empirical work has largely explored digital platforms in the context of young digital platforms [15, 16]. Only a small set of research explores how incumbent firms transition into the platform economy and how they need to change to benefit from platform economics [5, 7, 10, 17-19].

However, this stream of research has studied incumbents under the assumption that they can either build a platform or join an existing platform [3, 6], neglecting that incumbents can pursue multiple strategies (e.g. building and joining simultaneously). In addition, incumbents' platform strategies are largely investigated around the building and joining strategy, neglecting that incumbents also invest in platforms, acquire platforms, and utilize white-label platforms. To shed more light on platform strategies of incumbents, we pose the following research question: What strategies do incumbents follow towards participation in the platform economy, and what are their motivations?

To this end, we conduct a multiple case study with three incumbent firms from the chemical, construction, and banking industry. Our study makes two contributions. First, we extend the existing 
platform literature by empirically investigating the perspectives of incumbents. Second, and more specifically, we contribute to the discussion on how and why incumbent firms transition into the platform economy. Our results demonstrate that platform strategies cannot always be reduced to a simple build-or-join decision. In contrast, incumbents pursue multiple platform strategies at the same time. Their strategic options range from building and joining a platform over investing in and acquiring a platform to leveraging white-label platforms (that is, using the platform technology of a white-label platform owner to match the users of the incumbent with the complementors of the white-label platform). The two asset-heavy companies in our study largely draw on investing and joining strategies to avoid antitrust issues and build new sales channels. In contrast, the asset-light company is particularly engaging in the building and white-label strategy to remain in control of customer access and market-level data. All case companies agreed that it is crucial to enter the platform economy to pre-empt external companies from building strategically relevant positions.

The remainder of this paper is structured as follows. Section 2 analyzes the literature on platform strategies for incumbents and Section 3 describes our methodology. In Section 4, we present the intra-case analyses of three incumbents and in Section 5 the cross-case analysis. The paper concludes and presents limitations and future research in Section 6.

\section{Theoretical Background}

\subsection{Digital Platform Ecosystems}

Digital platforms have received significant attention from economics, technology management, information systems, and strategic management [13, 14]. Although different definitions of the term digital platforms exist across disciplines, the consensus is that digital platforms provide the basis for complementary products and services that can be developed and offered on the platform by third parties [8, 20]. Drawing from Evans and Gawer (2016) [21] and Cusumano, Gawer, and Yoffie (2019) [6], we distinguish between two distinct platform business models: innovation platforms and transaction platforms. An innovation platform refers to the technological foundation (e.g. iOS) on which complementors (e.g. software developers) develop complementary innovations (e.g. applications). Together with users, an innovation platform and its complementors form a platform ecosystem. A platform ecosystem describes a not fully hierarchically controlled coordination structure that integrates different actors through the directions set by a central company [22]. A transaction platform facilitates transactions between sellers and buyers (e.g. e-commerce platforms such as Amazon Marketplace or eBay) who would otherwise have difficulty finding each other. Platform owners refer to companies that exercise intellectual property rights and develop the technology of the platform. Platform providers refer to companies that represent users' primary point of contact with the platform [23]. Platform orchestrators refer to companies that are entitled to orchestrate the ecosystem by setting governance rules. Some companies pursue multiple roles. For instance, Google owns the platform Android and is also entitled to its orchestration while Samsung represents the platform provider as it sells the platform through its smartphone to users. In the present paper, we use the term platform owner to describe companies that reflect owners, providers, and orchestrators and the term platform provider (orchestrator) to describe companies that only provide (orchestrate) the platform.

\subsection{Platform Strategies}

The first strategy describes that an incumbent can enter the platform economy by investing in a digital platform separated from its organizational structure [24]. When following this strategy, the incumbent has two options. Either creating and investing in a spinoff (option A) or investing in an existing platform company (option B). Both options allow the incumbent to gain experience and learn about the platform's business model, success factors, and changing customer behaviors without having to adapt its existing business model. Hence, the incumbent can reap the benefits of what Zhang et al. (2018) call the Invest-Learn-Act strategy [18]. The disadvantage of this strategy is that the incumbent can't fully control the development of the platform and that the platform might move into directions detrimental to the incumbent's strategy. However, the higher the investment, the more control can be exercised.

The second strategy describes that an incumbent can enter the platform economy by building a digital platform integrated into its organizational structure [5]. For example, General Electric built an innovation platform by opening up its Predix operating system to external developers to harness complementary innovations and to equipment manufacturers to increase the side of application users [6]. Building a platform is advantageous when the market is relatively new and existing actors or technologies are not mature. The strategy also benefits the integration of the platform into the incumbent's existing 
structure and permits it to establish a keystone or leadership position in the market. The keystone position provides the opportunity to take advantage of network effects and to access market-level data, which can be used to enter the complementary or a new market more easily. However, the building strategy's challenges are that it is costly, timeintensive, and requires cooperation from other companies [10, 25]. To succeed, firms generally need deep pockets and a long-time horizon. Maybe even more challenging is that managers have to solve various platform challenges (e.g. build an installed base, pricing on each side, and governance mechanisms [19] and need to overcome the mindset of command and control $[10,17]$.

The third strategy describes that an incumbent can enter the platform economy by acquiring a digital platform and integrating it into its organizational structure [6]. That is, for example, the case for AccorHotels, who integrated the Onefinestay platform to be able to offer luxury properties in London to compete against emerging platforms within the hotel industry such as Airbnb [6]. The main advantage of acquiring a platform is that timeto-market is strongly reduced. However, this strategy requires incumbents to have mastered new, platformspecific management skills [19] such as facilitating open innovation and stimulating economic activity without exercising tight control. The challenge of buying a platform is to retain key talent, integrate the platform into legacy systems, and counteract cultural rejection [6].

The fourth strategy describes that an incumbent can enter the platform economy by joining a thirdparty digital platform [6]. When following this strategy, the incumbent has three options. They can join the supplier/complement producer side (option A), join the buyer/consumer side (option B), or join both sides as "prosumer" (option C). Joining a platform creates the opportunity to profit from platform economics such as increased reach and lower costs. However, once the third-party platform has become successful and established a dominant position, it might turn to become the incumbent's largest competitor. In the last years, it has been common for Amazon to act as a retailer on its marketplace and for Apple to compete with complementors on its innovation platform. Especially if the incumbent has not invested in the platform, it has almost no possibilities to influence the platform's decisions to its own advantages (exceptions are key complementors who are crucial to the platform's success).

Based on the proposed platform strategies, we argue that an incumbent uses a multi-platform strategy if it engages in at least two strategies (e.g. build and join) or uses a strategy at least twice (e.g. join two platforms). When an incumbent transitions from one strategy to another, we consider both exclusively pursuing the new strategy and pursuing multiple strategies at the same time as a multiplatform strategy. ${ }^{1}$

\section{Methodology}

We designed a multiple case study incorporating multiple semi-structured interviews and extensive online research. The qualitative case study approach is appropriate for investigating phenomena in a reallife context [26, 27]. We considered the perspective of incumbent companies that had decided to build or join one or more digital platform ecosystems. By analyzing both inter-case and cross-case patterns, we derived several industry-specific as well as some overarching patterns.

To explore how incumbents strategize within these rapidly changing environments, we chose a mixed sample of three large organizations. The case companies were selected under three essential selection criteria: (1) incumbents in their industries, meaning that the companies were established and operating successfully in their industries, (2) incumbents from different industries with different levels of digital maturity to avoid industry bias [28], and (3) incumbents that were actively involved in one or more digital platform ecosystems (as defined by Hein et al. [2]). The final sample comprised three case companies, one operating within the construction industry (a business-to-business [B2B] industry), the second in the chemical industry (a B2B industry), and the third in the banking industry ( $\mathrm{a}$ $\mathrm{B} 2 \mathrm{~B} /$ business-to-consumer [B2C] industry). All three incumbents originated before 1960, employed between 6,000 and 20,000 employees at the time of the study, and collected revenues between 2 and 20 billion euros.

In total, we conducted 11 semi-structured expert interviews. To strengthen the credibility of the results, we triangulated the interview data with additional secondary data as the main source of empirical material (see Table 1) [29].

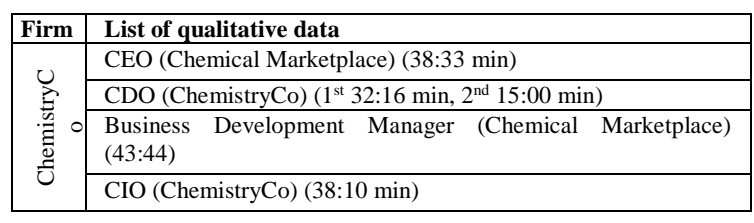

${ }^{1}$ We thank the anonymous reviewer for this comment 


\begin{tabular}{|c|c|}
\hline & $\begin{array}{l}2 \text { public interviews with } \mathrm{CDO}(\text { ChemistryCo) } \\
2 \text { public blog posts describing platform trends within the } \\
\text { industry }\end{array}$ \\
\hline \multirow{5}{*}{ 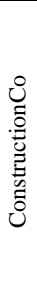 } & $\begin{array}{l}\text { CEO (Product-finder Platform) }+ \text { Head of Digital Innovation } \\
\text { Lab (ConstructionCo) }(53: 30 \mathrm{~min})\end{array}$ \\
\hline & Member of Digital Board (ConstructionCo) (56:39 min) \\
\hline & $\begin{array}{l}\text { Head of Business Development IoT (ConstructionCo) }(45: 38 \\
\text { min) }\end{array}$ \\
\hline & $\begin{array}{l}\text { Leader Business Unit Smart Building (ConstructionCo) (26:31 } \\
\text { min) }\end{array}$ \\
\hline & $\begin{array}{l}1 \text { Press release about the company } \\
1 \text { Blog posts describing platform trends within the industry }\end{array}$ \\
\hline \multirow{8}{*}{ 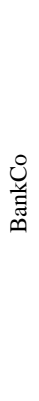 } & $\begin{array}{l}\text { Head Digital Commercial Offering \& Processes (BankCo) } \\
(41: 55 \mathrm{~min})\end{array}$ \\
\hline & $\begin{array}{l}\text { Product manager of Transaction Platform } 2 \text { (BankCo) }(44: 42 \\
\text { min) }\end{array}$ \\
\hline & Lead of Innovation Platform (BankCo) (27:58) \\
\hline & $\begin{array}{l}5 \text { public interviews with/ self-authored articles of the lead of the } \\
\text { innovation platform (BankCo) }\end{array}$ \\
\hline & 1 public speech of the company CEO (BankCo) \\
\hline & 1 public interview with the company $\mathrm{CDO}$ (BankCo) \\
\hline & 1 public interview with the white-label platform CEO \\
\hline & $\begin{array}{l}7 \text { press releases/ News articles on incumbent's platform strategy } \\
4 \text { Blog posts describing platform trends within the industry }\end{array}$ \\
\hline
\end{tabular}

Table 1: List of qualitative data

We analyzed the interview transcripts and additional selected data sources following the grounded theory methodology [30]. First, 168 open codes were generated from the transcripts and the data used for triangulation. Second, the similarities among the codes obtained by open coding were identified by axial coding. Consequently, 22 subcategories were grouped into eight categories. Table 2 is an example of the coding scheme.

\begin{tabular}{|l|l|l|}
\hline $\begin{array}{l}\text { Interview statement and } \\
\text { exemplary open codes } \\
\text { (underlined) }\end{array}$ & Subcategories & Categories \\
\hline $\begin{array}{l}\text { In the end, one concluded that it } \\
\text { is unlikely that these offers will } \\
\text { actually be successful afterwards, } \\
\text { it is perhaps more likely that }\end{array}$ & $\begin{array}{l}\text { 1) Pre-empt } \\
\text { pternal } \\
\text { platform } \\
\text { companies }\end{array}$ & $\begin{array}{l}\text { Incumbent } \\
\text { motivation }\end{array}$ \\
$\begin{array}{l}\text { someone like Amazon, eBay, or } \\
\text { Google will discover the whole }\end{array}$ & $\begin{array}{l}\text { 2) Industry } \\
\text { acceptance } \\
\text { thing for themselves }{ }^{l)} \text {. Then let's } \\
\text { father build something from } \\
\text { within the chemical industry that } \\
\text { bundles these areas of expertise, } \\
\text { as I said earlier, but then } \\
\text { operates independently } \text {. }\end{array}$ & \\
\hline
\end{tabular}

Table 2: Illustration of a coding scheme

Through an intra-case analysis, we investigated in detail the motives for the different platform strategies pursued by incumbents entering the platform economy and related them to the companies' industries. In the discussion, we elaborate on the differences and similarities among the pursued multiplatform strategies, along with their driving motivations.

\section{Results}

\subsection{Case 1: ChemistryCo}

Case description. ChemistryCo is an established, globally operating incumbent, leading a specific area of the specialty chemicals industry. Various sources confirmed the low digital maturity of this chemical industry. Until recently, only a small number of digital platforms have existed in this industry, leaving opportunities for introducing new platform ecosystems [31]. A few years ago, ChemistryCo started a digital transformation initiative focused on the development of digital business models along the value chain. Out of this initiative, the company founded a digital platform startup that developed a transaction platform called Chemical Marketplace. This platform connects buyers of chemicals to chemical suppliers of all sizes. It also plans the provision of additional services based on analytics. The incumbent is taking further platform initiatives; for example, the first considerations on an innovation platform are being formulated as part of the company's R\&D.

ChemistryCo' multi-platform strategy. The company initiated the development of the Chemical Marketplace transaction platform, which was built by a new separated platform organization. Hence, ChemistryCo became the investor of the created spinoff. After birthing the idea of an online marketplace for the chemical industry, the market was screened for existing solutions. The analysis at that time revealed no adequate platform in the western area. ChemistryCo decided to fill this gap and build something new.

We identified that the company had three reasons to separate the platform as a spin-off. The most commonly reported reason for separating the platform from the organization is industry acceptance. The incumbent soon realized that unless the platform was independent and separated from the parent company, "[Chemical Marketplace] would have become an extended sales arm of [ChemistryCo], not accepted by the market and then you are not a marketplace" (CDO, ChemistryCo). For this reason, the data worlds of the two companies are completely separated and ChemistryCo is not treated differently from other participants of the ecosystem. Second, "according to the antitrust laws of most countries, you are not allowed to sell complementary competing products on your own webshop. Because then, you would gain insight into customer relations, prices, and quantities and that is 
an antitrust" (CIO, ChemistryCo). Article 101 of the TFEU prohibits "agreements between undertakings" that can prevent or restrict competition [32]. When platform owners compete with complementors on the platform, they can potentially gain insights into competitively sensible information (e.g. prices), which might violate the above principle. To prevent the flow of information contrary to antitrust law, incumbents tend to spin off their platform operations as separate platform companies [33]. The third reason for separation was to cope with the different culture and competencies needed to operate the new platform. Separation from the founding company enables the platform company to attract the required workforce and achieve the required time to market. "Everyone who worked there [...] made a conscious decision to work for a startup rather than for a large chemical company and these are very different working environments" (CEO, Chemical Marketplace).

ChemistryCo revealed two motivations for investing in a spin-off. First, expecting that the platform trend from the B2C sector will spill over into the $\mathrm{B} 2 \mathrm{~B}$ sector, the company decided that by initiating a platform from within the industry, they could pre-empt platform startups or technology companies from outside the industry. Second, as a venture capital provider, ChemistryCo receives a share of the platform's revenues and aims to generate a positive return on investment when selling its shares.

However, ChemistryCo is not only the initiator and investor of Chemical Marketplace but also joined the platform as a complementor to use it as an additional sales channel.

Besides joining the transaction platform of the spin-off, the CDO also stated that: "When we sell in regions where [Chemical Marketplace] is not active, for example in China, we also use existing platforms in these regions."

In summary, ChemistryCo pursues multiple strategies (investing in spin-off, joining the spin-off's transaction platform, and joining transaction platforms of existing firms) at the same time in contrast to pursuing exclusively one strategy after another. While no synergies arise from joining multiple transaction platforms, ChemistryCo leveraged synergies between investing in a spin-off and joining the spin-off's platform. That is, by initiating and contributing to a new platform made by industry insiders, ChemistryCo pre-empts external companies from entering, which may represent a form of strategic vulnerability or future risk [34].

\subsection{Case 2: ConstructionCo}

Case description. ConstructionCo is an incumbent enterprise in the construction supply industry, leading the field of building envelopes. As the chemical industry, the construction industry is very complex and has a low level of digital maturity: "It's only been 1.5 years since the whole digitalization process really began to feel an upswing" (Member of Digital Board, ConstructionCo). Yet some of the majors in the industry, including ConstructionCo, have actively engaged in digitization and investments in digital companies and technology. A few years ago, ConstructionCo created a digital roadmap, exploring and developing digital solutions for different work phases accompanying typical construction projects. This roadmap inspired ConstructionCo's manufacturer-independent product-finder transaction platform (called Product-finder Platform), which extends beyond the core business of the company. The idea for this business model was then realized by founding a spin-off. Besides, the company is currently in the process of developing an IoT platform.

ConstructionCo's multi-platform strategy. The company decided to create and invest in a separated spin-off. The Product-finder platform enables a manufacturer-independent comparison of building products. Product-finder Platform satisfies our definition of a transaction platform because it digitally brings together planners and manufacturers.

As the reason for separation from the founding company, ConstructionCo identified the need for industry acceptance in the sense that "we wanted to be a manufacturer-independent and neutral platform (CEO, Product-finder Platform).

ConstructionCo revealed two motivations for investing in a spin-off. First, to pre-empt invading platform companies. According to the CEO of the Product-finder Platform, it is better to "shape than be shaped" as this strategic move allows to avoid high margins, negative dependencies on possible external platforms, and loss of control. As digital leaders, they can better serve the interests of their industry. Second, as an investor, ConstructionCo is also entitled to a proportionate revenue share of the spinoff's sales. In this respect, the company sees itself as a strategic partner who aims to establish a long-term business model in the market and a continuous revenue stream for itself.

In addition to investing in a spin-off transaction platform, ConstructionCo also joins the platform as a 
complementor by publishing its product information on top of the platform. In order to reach customers in geographic regions that the Product-finder platform does not address, ConstructionCo participates in transaction platforms of existing firms.

Moreover, ConstructionCo regularly screens the market for potential startups and technologies to invest in. Although this focus is not limited to platform companies, ConstructionCo took a majority stake in a transaction platform where architects and building product manufacturers can inform and exchange information about new products with videos.

Lastly, ConstructionCo is currently developing an Internet of Things (IoT) platform that will transfer the building envelope to the digital world and serve as a second business in addition to the traditional product business. To avoid dependencies and high fixed payments to external companies, and to ensure the development of know-how within its own company, ConstructionCo decided to build a new platform. The IoT platform is currently restricted to internal developers but might open up to third-party developers in the future, potentially turning into an innovation platform.

In summary, ConstructionCo pursues multiple strategies (investing in a spin-off and an existing firm, joining the spin-off's platform and transaction platforms of existing firms, and developing an innovation platform) simultaneously in contrast to pursuing exclusively one strategy after another. ConstructionCo leveraged synergies between investing in a spin-off and joining the spin-off's platform in the sense that ConstructionCo contributes to the success of a platform made by industry insiders. Hence, it pre-empts external companies from entering the industry, which may represent a future risk.

\subsection{Case 3: BankCo}

Case description. BankCo is an incumbent fullservice bank within the banking and financial services industry. Its customers include private clients, medium-sized companies, corporations, the public sector, and institutional investors. As customer expectations increase and more fintechs enter the market, banks have been under pressure to digitize for some time, so the industry is already digitally mature. With the ongoing digitalization of the industry and the blurring ecosystem boundaries, platforms are increasingly becoming the method of choice for incumbent financial services institutes, especially in the retail and commercial banking fields. Alongside the incumbents that are establishing themselves as platform owners and orchestrators, tech giants are gradually trying to invade the banking business with their platforms. Consequent to these developments, companies in the industry must decide whether to build or join one or more platform ecosystems. Our case company regards its customer relationships as its core competency. For this reason, it decided to become a platform owner and orchestrator. During the last two years, our case company has initiated and implemented numerous platform-based business models, including transaction platforms and an innovation platform.

BankCo's multi-platform strategy. BankCo has built a marketplace on which it no longer offers only its own financial products, but also external products provided by complementors. On top of Transaction Platform 1, BankCo offers several key services that are supplemented by so-called "beyond banking" offers, such as accounting tools provided by fintechs. Hence, BankCo is simultaneously platform owner and non-competing complementor of Transaction Platform 1.

The company revealed four motivations for building a transaction platform. By positioning itself as a platform owner, BankCo can access the customer data generated on the platform, and hence develop new business models and implement new features. The importance of this argument was heavily emphasized: "We believe that what we learn from these usage patterns and why a customer likes a product from another bank, from another provider, more than our own is worth much more than the few 100 product deals" (Head Digital Commercial Offering \& Processes, BankCo). Closely related to the above motivation, BankCo stated no desire to become a pure complementor because direct access to its customers is necessary for customer retention and must not be lost. "In the digital age, contact with customers is only maintained by those who offer them the best products, even if these are third-party offers" (Vice Chairman of the Management Board, BankCo). The company perceives tech giants, which also position themselves as platforms within the banking industry, as its greatest threat. Against this concomitant threat, the company is accelerating the pace of its own platform initiatives to pre-empt industry outsiders from entry. By positioning itself as a platform owner, BankCo also expects to increase its margins: "Whoever has the customer access gets the sales margin. And that grows from year to year. In contrast, the pure producer margin is getting smaller and smaller" (CDO, BankCo). This statement demonstrates that besides leveraging platforms for customer access (and hence gaining insights that 
improve the company's offerings), the company utilizes the platform's mediation service as a profitable business model.

In addition to Transaction Platform 1, BankCo uses a white-label platform to provide Transaction Platform 2, which customers can use to access deposit products offered on top of the platform by third parties. This white-label strategy describes the establishment of a transaction platform that integrates a white-label platform solution operated by an external company, instead of developing the platform infrastructure inhouse and from scratch. In our case, the marketplace frontends of Transaction Platform 2 are connected to a separately running instance of a white-label platform solution provided by a fintech. The complementary banks that offer deposit products are connected to the backend of the fintech platform. This backend is connected to the incumbent's frontends, which represents the customer interface of the platform. BankCo neither develops nor runs the platform technology; instead, it provides and orchestrates the platform. That means BankCo provides the platform interface to match offers with respective customers and is entitled to determine who is allowed to offer its products on the platform.

To illustrate, see figure 1 . At the center is the white-label platform owner (fintech) who connects complementary banks, who offer deposit products, to its platform.

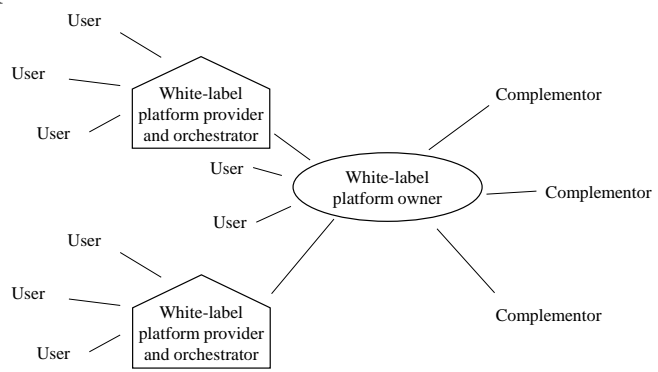

Figure 1: White-label platform strategy

In the simple case, the white-label platform owner matches these complementors to users in the sense that users can use the platform to decide which deposit they want to receive. However, if the user has no bank account for the complementary bank, she needs to open a new one. In the worst case, she would have to open multiple bank accounts to obtain multiple deposits. In order to counteract this inconvenience, the white-label platform owner partners with other banks as these have the possibility to use the user's existing bank account to manage multiple external deposits. Hence, users can access various third-party deposit products under the existing bank account without having to continuously create and switch bank accounts. Instead, users can handle deposit administration centrally. We termed these "partner banks" as white-label platform provider and orchestrator to illustrate that they provide and orchestrate the white-label platform under their own corporate brand ${ }^{2}$. As a result, the white-label platform strategy connects an incumbent who controls the user side with a platform company who controls the complementor side by granting the incumbent access to the platform.

In addition to the motivations identified for building Transaction Platform 1, BankCo named specific motivations for choosing the white-label platform strategy. On the one side, the company saves the costs of building a platform from scratch, and on the other side, BankCo can leverage the existing complementor ecosystem of the fintech to immediately offer various third-party products. Potential disadvantages of this strategy comprise strategic dependency, lack of control over technology development, and limited adoption of platform technology know-how.

Besides engaging in two transaction platforms, BankCo has built an innovation platform which provides third-party complementors access to a wide range of data and services via developer APIs. The decision to build the innovation platform was encouraged by the following motivations. First, the innovation platform is seen as an enabler for the the company's entire platform business model. By providing open APIs, the bank allows third-party developers to develop solutions that BankCo cannot develop itself. Moreover, by providing the best offer, the bank can differentiate itself from the competition, maintain existing customers, and win new customers. Second, BankCo financially participates in some of the solutions developed on the platform, and hence benefits from the growth of other companies. Furthermore, BankCo regards the complementor ecosystem of the innovation platform as a future opportunity for gaining partners in its marketplaces. Finally, BankCo monetizes the APIs, which reflects a new source of revenue.

In summary, BankCo pursues multiple strategies (building a transaction platform, joining the transaction platform, building an innovation platform, and using a white-label transaction platform) at the same time in contrast to pursuing exclusively one strategy after another. Although BankCo does not leverage any synergies between platform strategies

\footnotetext{
${ }^{2}$ Although the white-label platform owner neither provides the platform interface to the users of the "partner bank" nor is he entitled to its orchestration, we refer to him as owner as he provides the platform to its own users which he is also entitled to orchestrate.
} 
yet, the decision to join its Transaction Platform 1 as a complementor can generate synergies (e.g. preferential treatment of own complements) if BankCo decides to compete with complementors.

\section{Discussion}

The results provide initial evidence that industry characteristics influence platform strategies. In particular, the results indicate that customer group (B2B versus B2C), product type (physical product versus digital service), and sector-specific regulation influence the entry decision of industry outsiders, which again influences incumbents' platform strategies. In the following, we will use the term asset-heavy company (such as ChemistryCo and ConstructionCo) to describe companies that operate physical products in $\mathrm{B} 2 \mathrm{~B}$ industries and asset-light company (such as BankCo) to describe companies that offer digital services in B2C-oriented industries.

Industries that are characteristic by business customers, physical products, and restrictive regulation (such as the chemical and the construction industry) are more likely to reduce new entry and blurring industries, acting as significant barriers to entry. For instance, business customers require longterm and individually negotiated contracts, which reduce the applicability of standard prices and deliveries primarily adopted in B2C industries. Moreover, B2B markets have fewer customers than B2C markets, which limits the total value that can be extracted from network effects. While B2C industries are rather characterized by consumer homogeneity and significant network effects, within B2B industries, it is more difficult for industry outsiders to cope with the heterogeneity of business customers and harness network effects. In terms of the product type, producing physical products requires large investments in production facilities and compensating high variable costs. In contrast, digital services are characterized by marginal costs converting to zero. This is why it is less attractive and more difficult to enter existing product industries than industries with digital services. Lastly, sector-specific regulations represent another factor that influences new entry and blurriness of industries. On the one side, firms that operate in highly regulated industries acquired domain-specific knowledge such as reviewing whether the customer is allowed to acquire dangerous goods (e.g. chemical industry) or that products need to be sold through tenders (e.g. construction industries); knowledge which is difficult to obtain and to convert into operation as a new entry. On the other side, sector-specific regulation can also open an industry to new entry, as in the case of the Payment Service Directive in the financial industry.

To summarize, the results indicate that assetheavy companies operating in highly regulated industries mainly pursue the invest and join strategies. In contrast, the asset-light company, which was recently confronted with an opening of the industry, follows the build and white-label strategies. Based on the brief review of how industry characteristics influence entry decisions, we argue that asset-heavy companies significantly differ in their platform strategies compared to asset-light companies because they are less threatened by external firms gaining control over the industry's value chain. We observe that companies within an asset-heavy industry do not each aim to build a platform and engage in platform competition with other incumbents. In contrast, we observe that the industry accepts one neutral platform and does not aim to initiate competition on the platform level.

However, the industry characteristics are not the only reasons why companies do not pursue the build strategy. Another reason is that asset-heavy companies largely perceive platforms as an additional sales channel and less as "vehicle" to secure their business in the future. Hence, if one platform already exists for a specific market (mainly in terms of geography), these companies decide to join the platform instead of building a platform from scratch. The last reason is that, at least in the European Union, antitrust enforcement begins to prohibit platform owners to also act as competing complementors on their platforms. Hence, assetheavy companies risk regulatory intervention if they sell their products on their platform, rendering the building strategy unattractive. In order to counteract the possibility that a "neutral" platform develops in ways detrimental to the industry, some incumbents invest in platforms to ensure that the platforms act in the best interest of their respective industries.

Moving from asset-heavy industry to the assetlight industry, our findings illustrate that the assetlight company, which was recently confronted with an opening of the industry, pursues significantly different platform strategies; namely, the build and white-label strategy. The motivation behind these strategies can be attributed to the industry characteristics (deregulation in form of PSD2, digital services, and partially $\mathrm{B} 2 \mathrm{C}$ ), which reduce entry barriers and increase the threat of external firms gaining strategically relevant positions. That is, assetlight companies perceive a loss of control over customer access and market-level data, two components that critical to remain competitive and innovative in the future [34]. As a consequence, 
asset-light companies are forced to compete on the platform level. Figure two summarizes the different platform strategies.
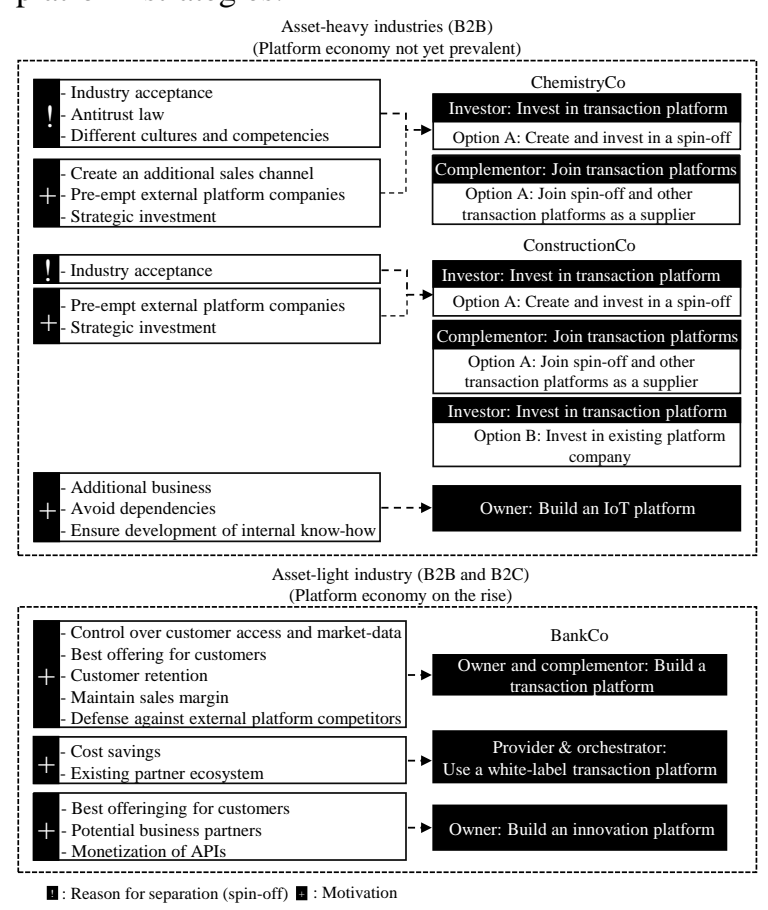

Figure 2: Multi-platform strategies followed by our case companies

\section{Conclusions}

Companies that operate digital platforms are growing rapidly. Theoretical and empirical research has largely explored digital platforms in the context of digital-native companies. Only a small set of research explores how incumbent firms transition into the platform economy and how they need to change to benefit from platform economics $[5,7,10$, 17-19]. However, this stream of research has studied incumbents under the assumption that they can either build a platform or join an existing platform.

In contrast, the results of our multiple case study on three incumbent companies from the chemical, construction, and banking industry demonstrate different insights. First, incumbents pursue multiple platform strategies simultaneously. They do not pursue exclusively one strategy after another. Second, platform strategies range from building and joining a platform over investing in and acquiring a platform to using white-label platforms. That is, using the platform technology of a white-label platform owner to match the users of the incumbent with the complementors of the white-label platform. Thus, the incumbent transitions into the role of a platform provider and orchestrator without becoming the owner of the platform. This strategy has the advantage of saving development and maintenance costs as well as immediately accessing an installed base of complementors. However, potential disadvantages include strategic dependency, lack of control over technology development, and limited adoption of platform technology know-how.

Moreover, our results provide initial evidence that industry characteristics influence platform strategies. We find that asset-heavy companies largely draw on investing and joining strategies, whereas the assetlight company is particularly engaging in building and white-label strategies. The invest and join strategies are primarily motivated by avoiding antitrust issues and building new sales channels. In contrast, the build and white-label strategies are mainly motivated by remaining in control over customer access and market-level data. Either way, all case companies agreed that it is crucial to enter the platform economy to pre-empt external companies from building strategically relevant positions.

For managers of incumbent firms, the results have three implications. First, the results demonstrate that managers should consider pursuing multiple platform strategies when transiting into the platform economy. This way, they can satisfy different customer groups and benefit from synergies. Second, the results indicate that managers should carefully consider whether they want to build a platform and join it as a complementor. Our case companies decided against this strategy as it reduces complementors acceptance of the platform and might lead to antitrust issues. Third, the new strategy of using a white-label platform reflects a promising strategy for managers who quickly need to solve the chicken-and-egg problem, remain in control over the orchestration of both sides, and do not want to build the platform technology.

Because our study is qualitative, it is necessarily limited by small sample size and low causal power. For future research, we encourage (1) to investigate other industries to extend our findings and draw conclusions from comparing different multi-platform strategies, (2) to consider how platform ownership (by a single company, consortium, or peer-to-peer network) influences multi-platform strategies, (3) to understand the competitive strategies for emerging winner-takes-all markets between native platform companies and incumbents (e.g. in the mobile payment context).

\section{References}


[1] Interbrand, Best Global Brands 2019 Rankings. 2019: https://www.interbrand.com/best-brands/best-globalbrands/2019/ranking/\#?listFormat=ls.

[2] Hein, A., et al., The influence of digital affordances and generativity on digital platform leadership, in 40th International Conference on Information Systems. 2019: Munich, Germany.

[3] Hein, A., et al., Digital platform ecosystems. Electronic Markets, 2019: p. 1-12.

[4] Hänninen, M., A. Smedlund, and L. Mitronen, Digitalization in retailing: multi-sided platforms as drivers of industry transformation. Baltic Journal of Management, 2018. 13(2): p. 152-168.

[5] Sebastian, I., et al., How big old companies navigate digital transformation. MIS Quarterly Executive, 2017. 16(3): p. 197-213.

[6] Cusumano, M.A., A. Gawer, and D.B. Yoffie, The Business of Platforms: Strategy in the Age of Digital Competition, Innovation, and Power. 2019: Harper Business.

[7] Van Alstyne, M.W., G.G. Parker, and S.P. Choudary, Pipelines, Platforms, and the New Rules of Strategy. Harvard Business Review, 2016. 94(4): p. 54-62.

[8] Parker, G.G., M.W. Van Alstyne, and S.P. Choudary, Platform Revolution: How Networked Markets Are Transforming the Economy? and How to Make Them Work for You. 2016: WW Norton \& Company.

[9] Constantinides, P., O. Henfridsson, and G.G. Parker, Platforms and infrastructures in the digital age. Information Systems Research, 2018. 29(2): p. 381-400.

[10] Svahn, F., L. Mathiassen, and R. Lindgren, Embracing Digital Innovation in Incumbent Firms: How Volvo Cars Managed Competing Concerns. MIS Quarterly, 2017. 41(1).

[11] de Reuver, M., C. Sørensen, and R.C. Basole, The digital platform: a research agenda. Journal of Information Technology, 2018. 33(2): p. 124-135.

[12] Rühl, G. and R. Kirkland, How a steel company embraced digital disruption. The McKinsey Quarterly, 2016.

[13] McIntyre, D., et al., Multi-sided platforms as new organizational forms. Academy of Management Perspectives, 2020(ja).

[14] McIntyre, D.P. and A. Srinivasan, Networks, platforms, and strategy: Emerging views and next steps. Strategic management journal, 2017. 38(1): p. 141-160.

[15] Rochet, J.-C. and J. Tirole, Platform competition in two-sided markets. Journal of the European Economic Association, 2003. 1(4): p. 990-1029.

[16] Baldwin, C.Y. and C.J. Woodard, The architecture of platforms: A unified view, in Platforms, Markets and Innovation, A. Gawer, Editor. 2009, Edward Elgar Publishing. p. 19-44.

[17] Sandberg, J., J. Holmström, and K. Lyytinen, Digitization and Phase Transitions in Platform Organizing Logics: Evidence from the Process Automation Industry. MIS Quarterly, 2020. 44(1): p. 129-153.

[18] Zhang, C., et al., Established Companies' Strategic Responses to Sharing Economy Threats. MIS Quarterly Executive, 2018. 17(1): p. 23-40.
[19] Schreieck, M., M. Wiesche, and H. Krcmar. MultiLayer Governance in Platform Ecosystems of Established Companies. in Academy of Management (AOM) Proceedings. 2018. Chicago.

[20] Cennamo, C., Competing in digital markets: A platform-based perspective. Academy of Management Perspectives, 2019(ja).

[21] Evans, P.C. and A. Gawer, The rise of the platform enterprise: a global survey. 2016.

[22] Jacobides, M.G., C. Cennamo, and A. Gawer, Towards a theory of ecosystems. Strategic Management Journal, 2018. 39(8): p. 2255-2276.

[23] Eisenmann, T.R., G. Parker, and M. Van Alstyne, Opening platforms: how, when and why?, in Platforms, Markets, and Innovations, A. Gawer, Editor. 2008, Edward Elgar Publishing: Cheltenham, UK.

[24] Christensen, C.M., The innovator's dilemma: when new technologies cause great firms to fail. 1997: Harvard Business Review Press.

[25] Schreieck, M., M. Wiesche, and H. Krcmar. How established companies leverage IT platforms for value cocreation-insights from banking. in Proceedings of the 25th European Conference on Information Systems (ECIS). 2017. Guimarães, Portugal.

[26] Eisenhardt, K.M., Building theories from case study research. Academy of Management Review, 1989. 14(4): p. 532-550.

[27] Yin, R.K., Case study research: Design and methods. Sage publications. Thousand oaks, 2009.

[28] Riasanow, T., et al., Core, intertwined, and ecosystemspecific clusters in platform ecosystems: analyzing similarities in the digital transformation of the automotive, blockchain, financial, insurance and IIoT industry. Electronic Markets, 2020.

[29] Davis, J.P. and K.M. Eisenhardt, Rotating Leadership and Collaborative Innovation : Recombination Processes in Symbiotic Relationships. Administrative Science Quarterly, 2011. 56(2): p. 159-201.

[30] Glaser, B. and A. Strauss, The Discovery of Grounded Theory: Strategies for Qualitative Research. 1967: Aldine. [31] Di Fiore, A. and G. Rosani, The age of platforms brings threats and opportunities for the chemical industry. 2018, LSE Business Review.

[32] European Union. Article 101 of the Treaty on the Functioning of the European Union. 2008 [cited 101; Available from: https://eur-lex.europa.eu/legalcontent/EN/TXT/HTML/?uri=CELEX:12008E101\&from= EN.

[33] Clemons, E.K. and J. Banattar. Regulating Online Privacy: Some Policy Guidelines, Including Guidelines for International Harmonization. in Proceedings of the 51st Hawaii International Conference on System Sciences. 2018.

[34] Schreieck, M., et al., Competing with Giant Platform Operators: An Analysis of Which Traditional Manufacturing Companies are at Risk from Strategic Dependence on Other Companies' Platforms in the Emerging Era of the Internet of Things, in Platform Strategy Research Symposium. 2019. 